\title{
Factors Affecting Palm Oil Price Based on Extremes Value Approach
}

\author{
Kantaporn Chuangchid ${ }^{1}$, Aree Wiboonpongse ${ }^{2}$, Songsak Sriboonchitta ${ }^{1} \&$ Chukiat Chaiboonsri $^{1}$ \\ ${ }^{1}$ Faculty of Economics, Chiang Mai University, Chiang Mai, Thailand \\ ${ }^{2}$ Faculty of Agriculture, Chiang Mai University, Chiang Mai, Thailand \\ Correspondence: Kantaporn Chuangchid, Faculty of Economics, Chiang Mai University, Chiang Mai, Thailand. \\ E-mail:kaekanta@hotmail.com
}

Received: September 3, 2012 Accepted: September 10, 2012 Online Published: November 2, 2012

doi:10.5539/ijms.v4n6p54 URL: http://dx.doi.org/10.5539/ijms.v4n6p54

\begin{abstract}
This study examines the dependence structure of extreme realization of growth rate between palm oil prices and factors affecting, which are soybean oil and crude oil prices. We employ the Bivariate Extreme Value methods for daily palm oil, soybean oil and crude oil prices ranging from July 1988 to January 2012. The results provide that the growth rate of palm oil and soybean oil prices has some dependence in extremes, but the growth rate of palm oil and crude oil prices has fairly weak dependence or even independence in extremes. Therefore, the authors of this study hoped that these findings not only have made a contribution to our understanding of what drives palm oil price movement of soybean oil and change in crude oil prices, but also for the practitioner who want to devise an updated model to enhance a further comprehension of the prices that drive these article of trade.
\end{abstract}

Keywords: dependence structure, bivariate extreme value, palm oil prices, soybean oil prices, crude oil prices

\section{Introduction}

In the consumption sector of oil and fats, palm oil is by far one of the highly well-known energy crop leaders in terms of production. The growth of palm oil production can be attributed to the demand of the local consumers as well as a price that is affordable to buy. The process of producing this natural wonder is made from a combination of other energy crops, such as soybean, sunflower, rapeseed and coconut oils (USDA, 2011). The factors that are involved in establishing the prices for palm oil are quite unique. With the rise in an increasing population, rapid economic growth and an elevated production of biodiesel, the worldwide demand for palm oil has brought about a changing shift towards the prices marked in palm oil. Such a rise in the factors will always lead to uncertainty or angst that makes decision making to sway by the extreme side such as hoarding the goods on part of the consumers while leaving scarce items for others (Khaneman, 2011). Nevertheless, it is a compelling fact that when there is an increase in crude oil and soybean oil prices, a recession in the world economy, and variations in the weather, the prices of palm oil tends to fluctuate. Figure 1 demonstrates the prices of palm oil fluctuating on a day to day basis that is based on these factors mentioned. Although uncertainty may be deemed as undesirable for nations that are trying to maintain the stability of palm oil prices, the advantages that it provides for other nations to reap some benefits in the international market are worth the venture. Therefore, for countries like Malaysia who involved in the palm oil plantation, they stand to gain the following: selling a product that is considered as one of the most competitively priced vegetable oil in the global market for the past 20 years and continues to be so today, being assured that the product is in the highest market penetration level of all vegetable oils (Dekeloil, 2012).

With the high price of palm oil, it influences more capital for investment and recruitment of labor to increase the production of palm oil. Since the price of palm oil is determined by many factors, the factor that influences palm oil prices is the availability of substitutes such as the prices of soybean oil. As an oil commodity, it has become an important influence on palm oil prices because of its similar application in the food industry (Rahman, Shariff, Abdullah, \& Sharif, 2007). Figure 2 shows the palm oil and soybean oil daily prices series. Moreover, the price of crude oil is also an important factor that influences palm oil prices. Because of the recent price increase in crude oil and growing environmental concerns, biodiesel has become an important alternative fuel that acts as the lifeblood of the retailing industries that are highly depended on the logistics and transportations to deliver their goods on time. Figure 3 demonstrates the daily price series of palm oil and crude oil. This information is of 
particular importance as it shows the movement of palm oil prices that is affected by the prices of soybean oil and crude oil.

In this study, we attempt to investigate the relationship between palm oil prices and the two factors (soybean oil and crude oil prices) with a daily data. Since the data demonstrates an apparent tendency for non-normal distribution (see in table 1), the way to proceed this is to use the extreme value theory and to model it as the tail of an extreme value distribution. The aim of this paper is to employ the bivariate extreme value to determine the dependence between the prices of palm oil and soybean oil, as well as the prices between palm oil and crude oil. The rest of the paper is structured as followed: Section 2 gives a literature review, Section 3 presents the data and methodologies, Section 4 discusses the empirical results, and finally Section 5 offers the conclusion.

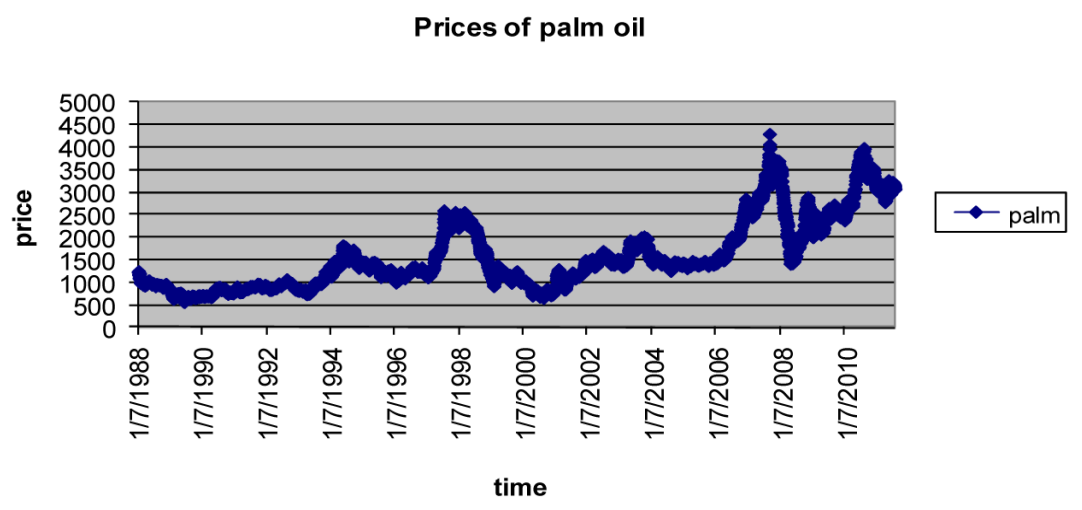

Figure 1. Palm oil daily price, Jul 1988 - Jan 2012

Source: Ecowin

Note: The Palm oil price of this paper is Palm Oil Futures 1-Pos, MYR

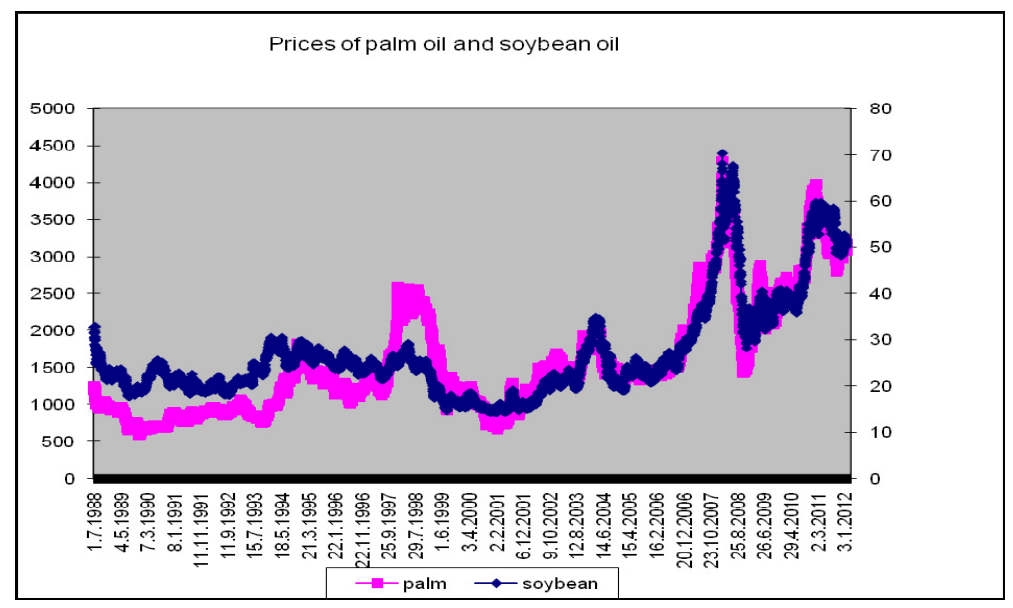

Figure 2. Palm oil and Soybean oil daily prices, Jul 1988 - Jan 2012

Source: Ecowin

Note: The Palm oil price of this paper is Palm Oil Futures 1-Pos, MYR, The Soybean oil price of this paper is Soybean Oil Futures 1-Pos, USD. 


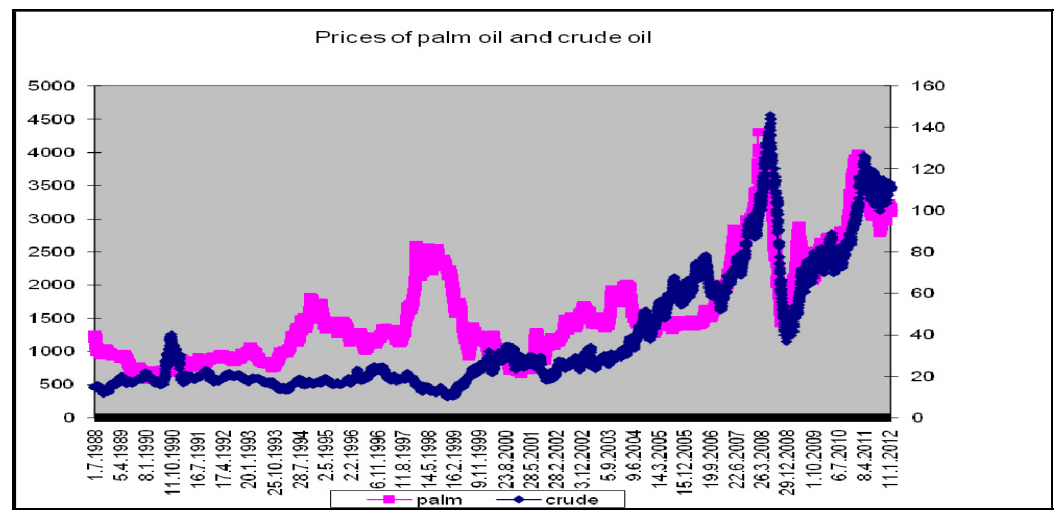

Figure 3. Palm oil and Crude oil daily price, Jul 1988 - Jan 2012

Source: Ecowin

Note: The Palm oil price of this paper is Palm Oil Futures 1-Pos, MYR, The Crude oil price of this paper is Brent Crude Futures 1-Pos, USD.

\section{Literature Review}

The authors of the study draw upon the fact that many palm oil producing countries have confirmed involvement with organizations and research institutes. When these two form into a working partnership, they become a unit that generate data and information that adds to the knowledge on oil palm cultivation, palm oil processing, and related applications. We see that Talib \& Darawi (2002) have studied upon a structural model for the purpose of describing the Malaysian palm oil industry from 1997 to 1999 by taking into account the total palm oil area, oil palm yield, domestic consumption, exports and imports. In their study, it was proclaimed that the importance of Malaysian economy and its affecting factors were palm oil stock level, price of palm oil, the exchange rate, world population, and the price of soybean oil. According to Wahid, Simeh, \& Nordin (2007) who have investigated the development in the world prices for palm oil, their findings considered that the impact of the trends on world palm oil price was derived from consumption, trade, price competitiveness, investment in oil $\mathrm{palm} / \mathrm{palm}$ oil, and the use of palm oil producing biodiesel. In relevance to this work, the high rise in the trend of the oil palm price had a great implication for the agricultural and industrial sector in producing countries (Pleanjai, Gheewala, \& Garivait, 2007). However, it's important to be aware on the fact that the price of oil palm surges over time due to the uncertain price of oil palm. Therefore, the work reminds us that there are risks and unreliability for tree-crop farmers, shareholder, traders, and producers. In order to configure the trends as a way for decreasing risk and uncertainties, there should be some effective risk management strategies implemented to ensure a sound policy to take for action (Karia \& Bujang, 2011).

Our review of the work comes across upon other scholars who have studied factors that affect prices of palm oil. There are some studies that indicate an existing relationship between soybean oil and palm oil prices. We refer to Arshad, Shamsudin, \& Hameed (2011) who described the soybean oil as a competitor to palm oil. Arhsad and his colleagues used the 'two stage least squares method' to estimate soybean and palm oil prices. With regards to the application employed, their work found that soybean prices would have a positive relationship with world palm oil price. Based on the analysis of relationship with Abdullah, Abas, \& Ayatollah (2007), his group reveals that soybean oil and palm oils are two good examples of agricultural commodities that have similar characteristics. They are also substitutable in many applications, and have prices of soybean and palm oil that are highly correlated.

In terms of the relationship between crude oil and palm oil prices, Hameed \& Arshad (2009) studied the relationship between the prices of crude oil and selected vegetable oils using the Granger causality test. According to this study, the results show that in the long-run there was a one direction relationship between crude oil price and the prices of each of four vegetable oils, i.e., palm, rapeseed, soybean, and sunflower oils, but the reverse was not true. Moreover, our work points to Hadi, Yahya, Shaari, \& Huridi (2011) studying the effect of changes in crude palm oil prices on the price of crude oil. Upon applying the Engle-Granger Cointegration test and Error Correction Model to find a significant long-term result, their work found that the prices of crude palm oil and crude oil are also positively correlated. However, we wish to mention that previous works assume that the data is normally distributed. Therefore, all of the aforementioned studies have suffered from this weakness of 
normality assumption since the prices of palm oil, soybean oil, and crude oil are assumed to have a non-normal distribution. In this paper we find that the extreme information flows from soybean oil and crude oil prices to palm oil prices.

We assert that the Extreme Value Theory (EVT) provides a strong theoretical basis where we can construct statistical models that are capable of describing extreme events (Gilli \& Kellezi, 2006). Extreme value methods have been used in environmental science, hydrology, insurance, and finance. Furthermore, EVT can describe the behavior of random variables both at extremely high or low levels. The theory enables us to describe the performance of the heavy-tail properties of a high frequency time series data, such as financial returns (Onay \& Unal, 2012). Univariate extreme value theory was used to analyze and evaluate extreme risks in finance and disaster sector. In addition, the bivariate EVT was used in studied on financial and disaster, such as Brodin \& Rootzen (2009) who have used univariate and bivariate extreme value methods for predicting extreme wind storm losses. Based on their study, they believed that the bivariate model provided the most realistic picture of the real uncertainties. To substantiate this idea, Escalante-Sandoval (2007) used bivariate extreme value distribution to analyze the flood frequency. According to his results, it showed that estimating the parameters of marginal distribution with bivariate reduced the standard error of fit than pair of univariate distribution.

\section{Data and Methodology}

The research instruments used in this study involve bivariate extreme value. Time series data of this paper was obtained from Ecowin. In this paper, the palm oil price is Palm Oil Futures 1-Pos, MYR, the soybean oil price is Soybean Oil Futures 1-Pos, USD and the crude oil price is Brent Crude Futures 1-Pos, USD. We took daily prices in palm oil, soybean oil and crude oil in local currencies and converted to growth rate of prices. Daily prices are computed as growth rate of prices relatives: $\mathrm{Gr}=\left(\mathrm{p}_{\mathrm{t}}-\mathrm{p}_{\mathrm{t}-1}\right) / \mathrm{p}_{\mathrm{t}-1} * 100$, where $\mathrm{p}_{\mathrm{t}}$ is the daily futures 1-Pos price at time t. The study period was from July 1988 till January 2012.

\subsection{Bivariate Extreme Value}

The Extreme Value Theory (EVT) is a concept of modeling and measuring extreme events which occur with a very small probability (Brodin \& Kluppelberg, 2008). There are two principal approaches to identify extremes in real data, Block Maxima (BM) and Peaks-Over Threshold (POT). BM and POT are central for the statistical analysis of maxima or minima and exceedances over a higher or lower threshold (Lai \& Wu, 2007). In this research, we use both bivariate BM and POT models to analyze the relationship between the prices of soybean oil and palm oil, as well as on the prices of crude oil and palm oil.

\subsection{Bivariate Block Maxima}

This method is concerned with parametric and non-parametric cases. In this study, we choose the parametric models. A brief summary of bivariate BM is given below:

Let $(\mathrm{X}, \mathrm{Y})$ denote a bivariate random vector representing the component-wise maxima of an i.i.d. sequence over a given period of time. Under the appropriate conditions the distribution of $(\mathrm{X}, \mathrm{Y})$ can be approximated by a bivariate extreme value distribution (BEVD) with c.d.f. G. The BEVD is determined by its two univariate margins $G_{1}$ and $G_{2}$ respectively, which are necessarily EVD, and by its Pickands dependence function A (Rakonczai \& Tajvidi, 2010).

$$
G(x, y)=\exp \left\{\log \left(G_{1}(x) G_{2}(y)\right) \times A\left(\frac{\log \left(G_{2}(y)\right)}{\log \left(G_{1}(x) G_{2}(y)\right)}\right)\right\}
$$

$\mathrm{A}(\mathrm{W})$ is responsible for capturing the dependence structure between the margins and determines only up to the condition that it is convex, passes through the points $(0,1),(1,1)$ and $(1 / 2,1 / 2)$ binds the upper left and right corners. The properties of function A are (1) $A(\mathrm{w})$ is convex, (2) $\max \{(1-\mathrm{w}), \mathrm{w}\} \leq A(\mathrm{w}) \leq 1$ and (3) $A(0)=A(1)$ $=1$. Rakonczai and Tajvidi, (2010) explained in their paper that the lower bounds in the second item of the properties of A corresponds to the complete dependence $G(x, \mathrm{y})=\min \{G 1(x), G 2(\mathrm{y})\}$, while the upper bound corresponds to (complete) independence $G(x, \mathrm{y})=G 1(x) G 2(\mathrm{y})$.

In this BM case, we chose one parametric models form nine models, which minimizes AIC (Akaike Information Criterion), to use for $\mathrm{A}(\mathrm{w})$ is logistic distribution function. Details about these and other models can be found in Stephenson (2011).

The logistic distribution function with parameter dep $=r$ is

$$
G(x, y)=\exp \left[-\left(x^{\frac{1}{r}}+y^{\frac{1}{r}}\right)^{r}\right]
$$


where $0<r \leq 1$. The independence case corresponds to $r=1$. For $r \rightarrow 0$, we get complete dependence.

\subsection{Bivariate Threshold Exceedances}

There are at least two ways of defining exceedances in higher dimensions. In the first definition, a distribution is fitted to the observations $\left\{(\mathrm{x}, \mathrm{y}) \mid(\mathrm{x}, \mathrm{y})>\left(u_{x}, u_{y}\right)\right\}$ where $u_{x}$ and $u_{y}$ are suitable thresholds for each margin. Second definition aims to fit a distribution to $\left\{(\mathrm{x}, \mathrm{y}) \mid(\mathrm{x}, \mathrm{y})<\left(u_{x}, u_{y}\right)\right\}$ where $\left(u_{x}, u_{y}\right)$ is defined as before. These distributions will be called Type I and Type II bivariate generalized Pareto distributions (BGPD), respectively (Coles \& Tawn, 1991), (Coles, 2001).

In this study, the strength of the dependence between extreme prices of palm oil and soybean oil, palm oil and crude oil is estimated by fitting joint exceedances to bivariate extreme value distribution using BGPD type I. From univariate GPD, the details for approximating the tail of $\mathrm{X}$ by

$$
\begin{gathered}
G(x)=1-\eta_{u}\left(1+\xi \frac{x-u}{\sigma}\right)^{-\frac{1}{\xi}}, x \geq u \\
\eta_{u}=P(X>u)
\end{gathered}
$$

Suppose $\left(x_{1}, y_{l}\right), \ldots .,\left(x_{n}, y_{n}\right)$ are independent realizations of a random variable $(X, Y)$ with joint distribution function $F(x, y)$ on regions of the from $x>u_{x}, y>u_{y}$, for large enough $u_{x}$ and $u_{y}$. The marginal distributions of $F$ each have an approximation of equation (3), with respective parameter sets $\left(\eta_{x}, \sigma_{x}, \xi_{x}\right)$ and $\left(\eta_{y}, \sigma_{y}, \xi_{y}\right)$ (Coles, $2001)$. We can approximate the tail of $\mathrm{X}$ and $\mathrm{Y}$ for $x>u_{x}, y>u_{y}$ with $G\left(x: \eta_{x}, \sigma_{x}, \xi_{x}\right)$ and $G\left(y: \eta_{y}, \sigma_{y}, \xi_{y}\right)$, respectively. The Bivariate Generalized Pareto Distributions (BGPD) type I is

$$
\mathrm{G}(\mathrm{x}, \mathrm{y})=\exp \{-\mathrm{V}(\mathrm{x}, \mathrm{y})\}, \mathrm{x}>0, \mathrm{y}>0
$$

The dependence functions of this case use The Husler-Reiss models (palm oil and soybean oil prices) and asymmetric negative logistic models (palm oil and crude oil prices). A brief summary of these models are given below:

The Husler-Reiss (HR) distribution function with parameter dep $=r$ is

$$
G(x, y)=\exp \left(-x \Phi\left\{r^{-1}+\frac{1}{2} r[\log (x / y)]\right\}-y \Phi\left\{r^{-1}+\frac{1}{2} r[\log (y / x)]\right\}\right)
$$

where $\Phi($.$) is the standard normal distribution function and r>0$. Independence is obtained in the limit as $r \rightarrow 0$. Complete dependence is obtained as $r$ tends to $\infty$.

The asymmetric negative logistic distribution function with parameters dep $=r$ and asy $=\left(t_{1}, t_{2}\right)$ is

$$
G(x, y)=\exp \left\{-x-y+\left[\left(t_{1} x\right)^{-r}+\left(t_{2} y\right)^{-r}\right]^{-1 / r}\right\}
$$

where $r>0$ and $0<t_{1}, t_{2} \leqslant 1$ When $t_{1}=t_{2}=1$, the model reduces to the negative logistic model. Independence is obtained in the limit as either $r, t_{1}$ or $t_{2}$ approaches zero. Complete dependence is obtained in the limit when $t_{1}=t_{2}=1$ and $r$ tends to infinity (Stephenson, 2011).

\section{Empirical Results}

Table 1 presents the descriptive statistics of the growth rate of palm oil, soybean oil and crude oil prices. An examination of the descriptive table reveals that most of the growth rates of 3 oil prices have excess kurtosis, which indicates the influence of extremes on all growth rates of prices distributions. The Jarque-Bera test rejects normality at $5 \%$ level for all distributions.

Table 1. The descriptive statistics of growth rates of palm oil, soybean oil and crude oil prices

\begin{tabular}{lccc}
\hline & PALM & SOYBEAN & CRUDE \\
\hline Mean & 0.0277 & 0.0179 & 0.0581 \\
Median & 0 & 0 & 0.0425 \\
Maximum & 10.4275 & 8.3707 & 14.0545 \\
Minimum & -10.8527 & -7.4739 & -34.7682 \\
Std. Dev. & 1.6032 & 1.4669 & 2.2289 \\
Skewness & 0.0952 & 0.1306 & -0.5933 \\
Kurtosis & 8.2815 & 5.5438 & 16.5524 \\
\hline
\end{tabular}




\begin{tabular}{lccc}
\hline Jarque-Bera & 7159.42 & 1676.162 & 47440.95 \\
Probability & 0 & 0 & 0 \\
Observations & 6152 & 6152 & 6152 \\
\hline
\end{tabular}

\subsection{Bivariate Block Maxima}

We use the growth rate of prices daily data into blocks of equal length and fit it to the maximums of monthly. In case of BM, we chose the logistic parametric model which minimizes AIC from nine models, to find the dependence functions between growth rate of palm oil and soybean oil prices and between growth rate of palm oil and crude oil prices.

The test results from using bivariate BM are shown in table 2. This table reveals distribution function parameter $(r)$ and estimates for the location $(\mu)$, shape $(\xi)$ and scale $(\sigma)$ parameters. The logistic model between growth rate of palm oil and soybean oil prices has $r$ estimate equal 0.83 , which implies that growth rate of palm oil and soybean oil prices has dependence in extremes but not strong enough. Figure 4 shows dependence between monthly maxima of growth rate of palm oil and soybean oil prices in which figure 5 confirms this information. And the logistic model between growth rate of palm oil and crude oil prices has $r$ estimate equal 0.90 , thus indicating that it has dependence but fairly weak in extremes between palm oil and crude oil prices. There is a fairly weak dependence between monthly maxima of growth rate of palm oil and crude oil prices; as shown in figure 6 and confirmed by figure 7 .

Table 2. Bivariate block maxima palm oil and soybean oil prices, palm oil and crude oil prices

\begin{tabular}{lccccccccc}
\hline & BM & AIC & $\mu_{1}$ & $\sigma_{1}$ & $\xi_{1}$ & $\mu_{2}$ & $\sigma_{2}$ & $\xi_{2}$ & $r$ \\
& model & & & & & & & & \\
\hline Palm-soybean & logistic & $1,912.587$ & 2.0922 & 1.1316 & 0.1464 & 2.2733 & 1.0217 & 0.0183 & 0.8325 \\
& & & $(0.0768)$ & $(0.0595)$ & $(0.0482)$ & $(0.0681)$ & $(0.0496)$ & $(0.0419)$ & $(0.0379)$ \\
Palm-crude & logistic & $2,138.662$ & 2.0923 & 1.1394 & 0.1605 & 3.1068 & 1.3558 & 0.1654 & 0.9019 \\
& & & $(0.0773)$ & $(0.0602)$ & $(0.0501)$ & $(0.0912)$ & $(0.0707)$ & $(0.0472)$ & $(0.0384)$ \\
\hline
\end{tabular}

Note: Terms in parentheses are standard errors of parameter estimates.

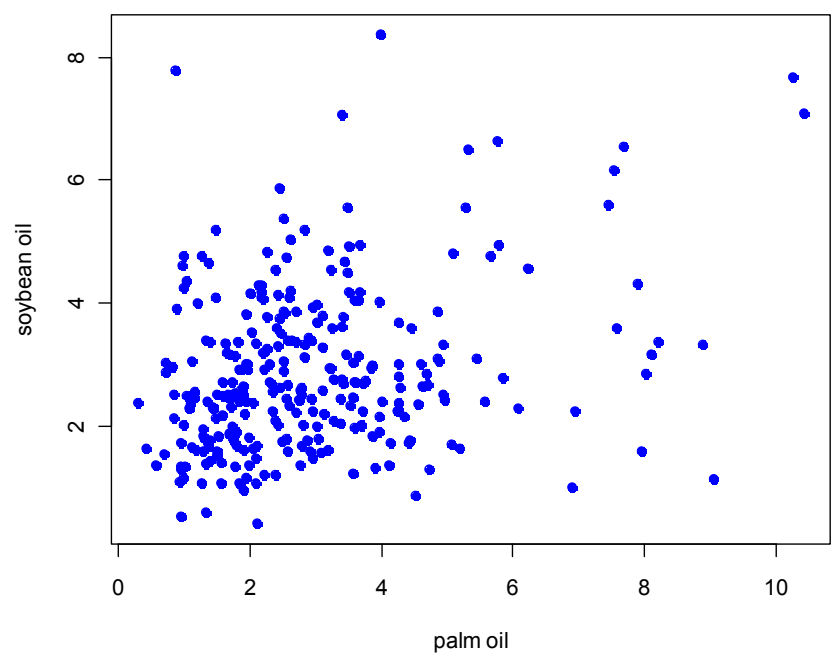

Figure 4. Bivariate monthly maxima of growth rate of palm oil and soybean oil prices 

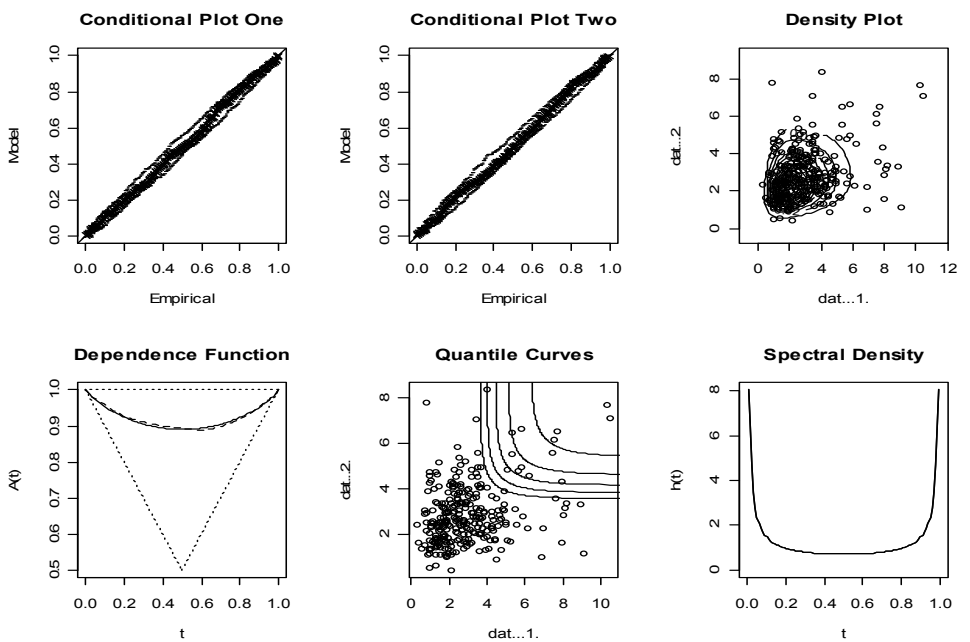

Figure 5. The bivariate logistic distribution function between growth rate of palm oil and soybean oil prices

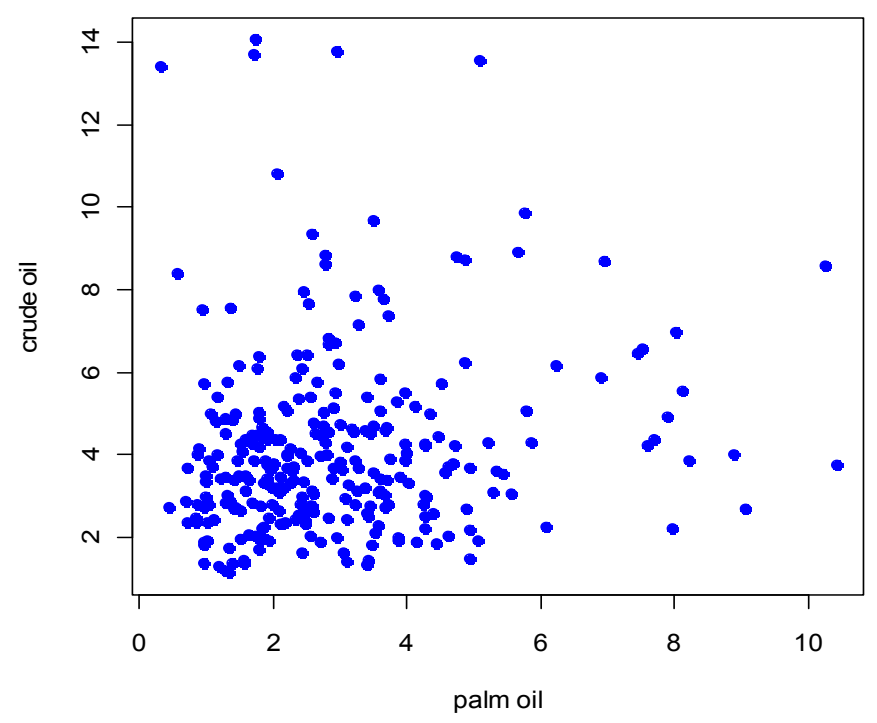

Figure 6. Bivariate monthly maxima of growth rate of palm oil and crude oil prices 


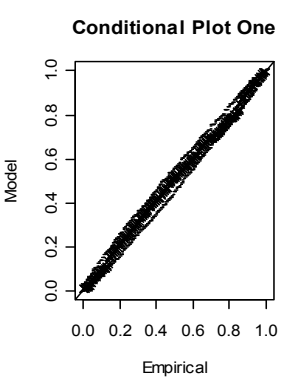

Dependence Function

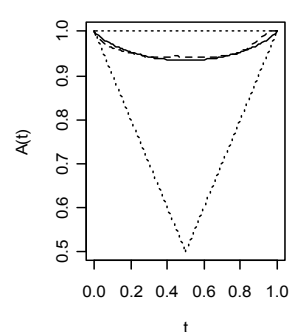

Conditional Plot Two

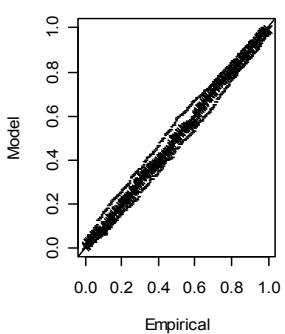

Empirical

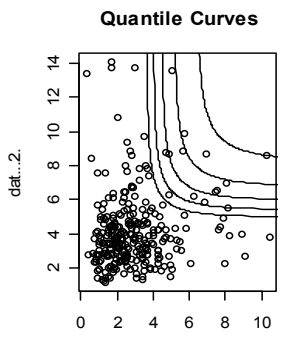

dat...1.
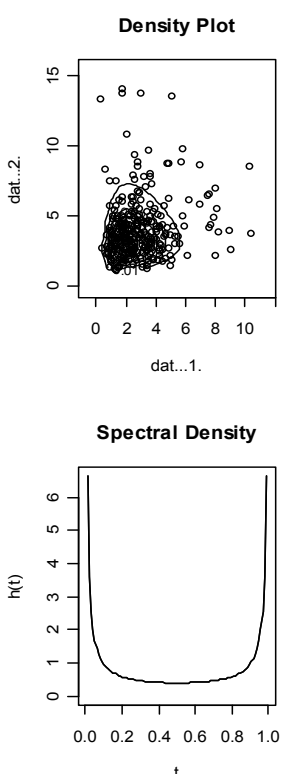

Figure 7. The bivariate logistic distribution function between growth rate of palm oil and crude oil prices

\subsection{Bivariate Threshold Exceedances}

We used the growth rate of prices daily data and analyzed the data by modeling exceedances of prices over a threshold. In this case, the dependence in extremes between palm oil and soybean oil prices uses HR models, which minimize AIC from nine models. And the asymmetric negative logistic model is used to find the dependence in extremes between palm oil and crude oil prices.

Table 3 presents the result of the bivariate threshold exceedances analysis of the distribution function parameter $(r)$ and estimates for the shape $(\xi)$ and scale $(\sigma)$ parameters between growth rate of palm oil and soybean oil prices, growth rate of palm oil and crude oil prices. The HR model has $r$ approach to one that means growth rate of palm oil and soybean oil prices has dependence in extremes. Figure 8 shows dependence in daily growth between palm oil and soybean oil prices and figure 9 provides the information that confirms it. On the other hand, the asymmetric negative logistic model has $t_{1}, t_{2}$ estimate approach to zero, thus implying that there is independence in daily growth between palm oil and crude oil prices. There is independence in daily growth between palm oil and crude oil prices, where figure 10 presents the data and figure 11 confirms it.

Table 3. Bivariate threshold exceedances palm oil and soybean oil prices, palm oil and crude oil prices

\begin{tabular}{lccccccccc}
\hline & GPD & AIC & $\sigma_{1}$ & $\xi_{1}$ & $\sigma_{2}$ & $\xi_{2}$ & $t_{1}$ & $t_{2}$ & $r$ \\
& model & & & & & & & & \\
\hline Palm-soybean & HR & $6,238.004$ & 1.2265 & 0.1005 & 0.9939 & 0.0437 & & & 0.6605 \\
& & & $(0.1070)$ & $(0.0651)$ & $(0.0850)$ & $(0.0636)$ & & & $(0.0358)$ \\
Palm-crude & aneglog & $6,602.384$ & 1.2023 & 0.1037 & 1.3726 & 0.1773 & 0.0256 & 0.0795 & 3.411 \\
& & & $(0.1047)$ & $(0.0663)$ & $(0.1218)$ & $(0.0684)$ & $(0.0132)$ & $(0.0477)$ & $(2.1834)$ \\
\hline
\end{tabular}

Note: Terms in parentheses are standard errors of parameter estimates. 


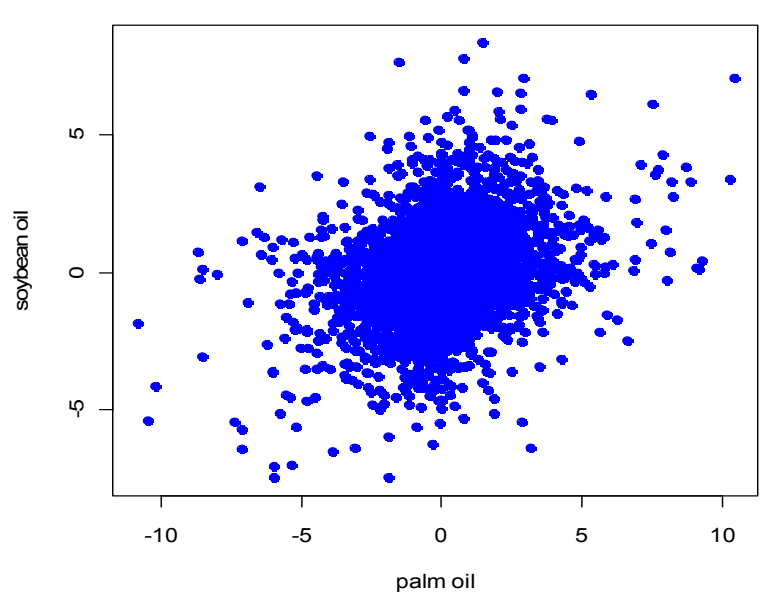

Figure 8. Bivariate threshold exceedances of growth rate of palm oil and soybean oil prices
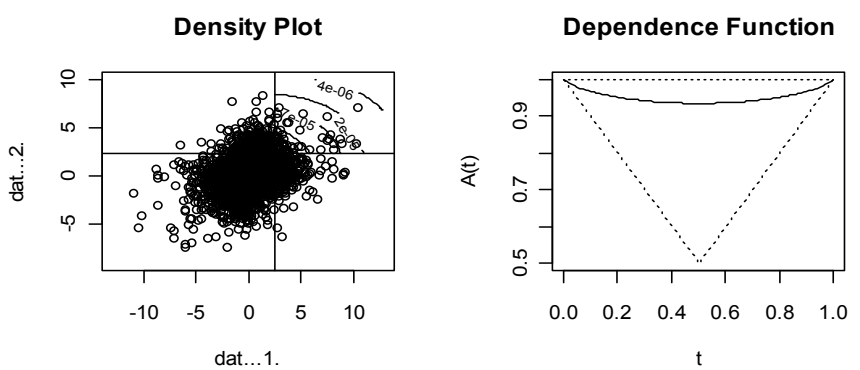

dat...1.

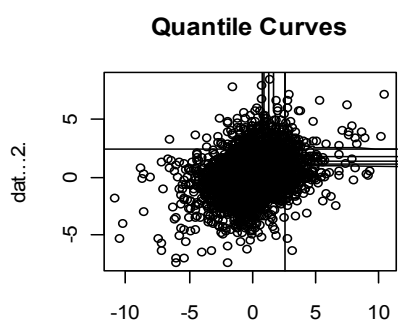

Spectral Density

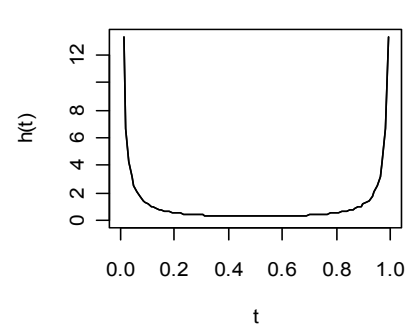

Figure 9. The bivariate HR distribution function between growth rate of palm oil and soybean oil prices 


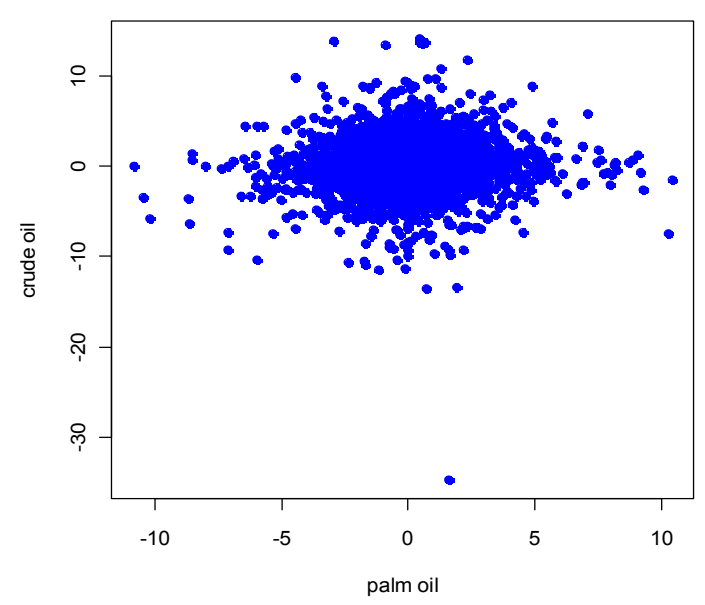

Figure 10. Bivariate threshold exceedances of growth rate of palm oil and crude oil prices

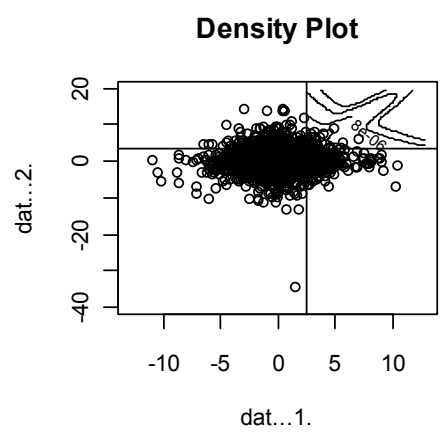

Quantile Curves

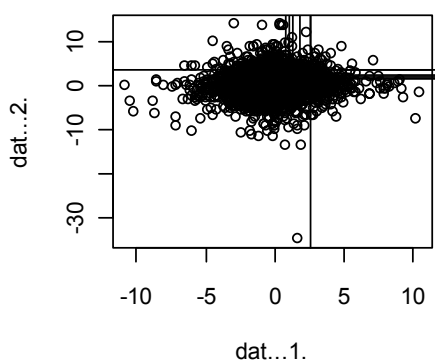

Dependence Function

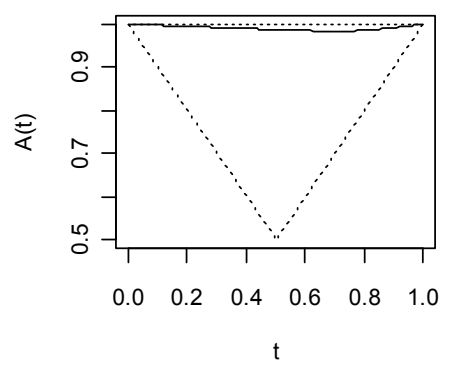

Spectral Density

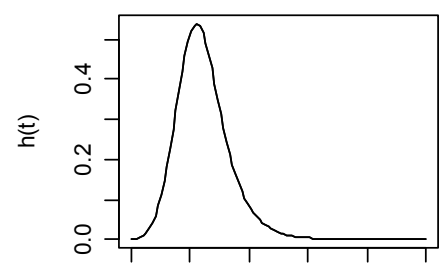

$\begin{array}{llllll}0.0 & 0.2 & 0.4 & 0.6 & 0.8 & 1.0\end{array}$

Figure 11. The bivariate asymmetric negative logistic distribution function between growth rate of palm oil and crude oil prices

\section{Conclusion}

This study focuses on the factor affecting palm oil prices. The work attests that there are many factors involved in the movement of palm oil prices. Such a movement has affected the prices of Soybean oil and crude oil as well. The aim of this study is to find the extreme dependence between palm oil and soybean oil prices, palm oil and crude oil prices using the bivariate extreme value. To do this, the paper applies the Bivariate Block Maxima and Bivariate Threshold Exceedances approach to examine the extreme dependence between the growth rate of palm oil and soybean oil prices, and the growth rate of palm oil and crude oil prices. Based upon our application, we see that the results of this paper show that both methods have a similar outcome. The growth rate of palm oil and soybean oil prices has some dependence in extremes. However, in the case of the growth rate of palm oil and 
crude oil prices, it has fairly weak dependence or even independence in extremes. Therefore, the authors of this study hoped that these findings not only have made a contribution to our understanding of what drives palm oil price movement of soybean oil and change in crude oil prices, but also for the practitioner who want to devise an updated model to enhance a further comprehension of the prices that drive these article of trade.

\section{Acknowledgements}

We wish to express particular thanks to Prof. Nader Tajvidi for his helpful suggestions and comments. We are grateful for Mr. Ravee Phoewhawm for providing the technical support. The authors wish to thank the Thailand Research Fund (TRF) for its financial support for the research project (BRG5380024).

\section{References}

Abdullah, R., Abas, R., \& Ayatollah, K. (2007). Impact of Palm Oil-based Biodiesel Demand on Palm Oil Price. Oil Palm Industry Economic Journal, 7(2), 19-27.

Arshad, F., Shamsudin, M. N., \& Hameed, A. A. (2011). An Econometric Analysis of the Link between Biodiesel Demand and Malaysia Palm Oil Market. International Journal of Business and Management, 6(2), 35-45. Retrieved from www.ccsenet.org/journal/index.php/ijbm/article/view/9162

Brodin, E., \& Kluppelberg, C. (2008). Extreme Value Theory in Finance. In Encyclopedia of Quantitative Risk Analysis and Assessment. http://dx.doi.org/10.1002/9780470061596.risk0431

Brodin, E., \& Rootzen, H. (2009). Univariate and bivariate GPD methods for predicting extreme wind storm $\begin{array}{llll}\text { losses. Insurance: } \quad \text { Mathematics and } & \text { 345-356. }\end{array}$ http://dx.doi.org/10.1016/j.insmatheco.2008.11.002

Coles, S. G. (2001). An introduction to statistical modeling of extreme values. In Springer-Verlag London Limited. http://dx.doi.org/10.1111/j.0006-341x.2002.01038.x

Coles, S. G., \& Tawn, J. A. (1991). Modelling Extreme Multivariate Events. Journal of the Royal Statistical Society. Series B (Methodological), 53(2), 377-392. Retrieved from http://www.jstor.org/stable/2345748

Dekeloil. (2012, August 10). Retrieved from http://www.dekeloil.com/nrg_pl_advantages.html

Escalante-Sandoval, C. (2007). Application of bivariate extreme value distribution to flood frequency analysis: a case study of Northwestern Mexico. Nat Hazards, 42, 37-46. http://dx.doi.org/10.1007/s11069-006-9044-7

Gilli, M., \& Kellezi, E. (2006). An Application of Extreme Value Theory for Measuring Financial Risk. Computational Economics, 27(2), 207-228. http://dx.doi.org/10.1007/s10614-006-9025-7

Hadi, A. R., Yahya, M. H., Shaari, A. H., \& Huridi, M. H. (2011). Investigating Relationship Between Crude Palm Oil and Crude Oil Prices-Cointegration Approach. 2nd International Conference on Business and Economic Research Proceeding, No.2011-281, pp. 1554-1565. Retrieved from http://www.international conference.com.my/proceedi...g\%20Relationship.pdf

Hameed, A. A., \& Arshad, F. M. (2009). The Impact of Petroleum Prices on Vegetable Oils Prices: Evidence from Co-integration Tests. Oil Palm Industry Economic Journal, 9(2), 31-40. Retrieved from http://purl.umn.edu/46251

Karia, A. A., \& Bujang, I. (2011). Progress Accuracy of CPO Price Prediction: Evidence from ARMA Family and Artificial Neural Network Approach. International Research Journal of Finance and Economics, 64, 66-79.

Khaneman, D. (2011). Thinking Fast and Slow. In A. Lane, Penguin Books (p. 137). London, England.

Lai, L., \& Wu, P. (2007). An Extreme Value Analysis of Taiwan's Agriculture Natural Disaster loss data. International Conference on Business and Information (BAI). Tokyo, Japan.

Onay, C., \& Unal, G. (2012). Cointegration and Extreme Value Analyses of Bovespa and the Istanbul Stock Exchange. Finance a uver-Czech Journal of Economics and Finance, 62(1), 66-91. http://dx.doi.org/10.2139/ssrn.1636183

Pleanjai, S., Gheewala, S. H., \& Garivait, S. (2007). Environment evaluation of biodiesel production from palm oil in a life cycle perspective. Asian Journal of energy environment, 8(1\&2), 15-32.

Rahman, A. K., Shariff, F. M., Abdullah, R., \& Sharif, N. H. (2007). Price Volatility Spill Over in the Malaysian Palm Oil Industry. Oil Palm Industry Economic Journal, 7(1), 24-32. 
Rakonczai, P., \& Tajvidi, N. (2010). On Prediction of Bivariate Extreme. International Journal of Intelligent Technologies and Applied Statistics, 3(2), 115-139.

Stephenson, A. (2011). Functions for extreme value distributions. Package 'evd', Version 2.2-4.

Talib, B. A., \& Darawi, Z. (2002). An Economic Analysis of the Malaysian Palm Oil Market. Oil Palm Industry Economic Journal, 2(1), 19-27.

United States Department of Agriculture, F. A. (2011, May 5-11). Oilseeds: World Markets and Trade. Retrieved from http://www.fas.usda.gov/oilseeds/Current/

Wahid, M. B., Simeh, M. A., \& Nordin, J. (2007). Recent Development in the World Palm Oil Prices: An Overview. Oil Palm Industry Economic Journal, 7(2). 